\title{
Grid Based Temperature and Relative Humidity Distribution Map of the Kathmandu Valley
}

\author{
Sangeeta Maharjan* and Ram P. Regmi \\ Central Department of Physics \\ Tribhuvan University, Kirtipur, Kathmandu, Nepal. \\ ${ }^{\star}$ Email: sangeetamaharjan@gmail.com
}

\begin{abstract}
Kathmandu valley has seen visible transformations in its intrinsic climate in recent decades. The atmosphere of the Kathmandu valley has become increasingly uncomfortable, unhealthy and more susceptible to, so far, unanticipated viral and other diseases. The lack of spatial distribution and temporal variation of potential climatic parameters as well as future scenarios have given rise to serious uncertainties with respect to climate change and development of adaptation strategies for sustainable climate of the valley and beyond. An accurate assessment and gridded documentation of prevailing climate at desired resolution is instrumental. Present study has been carried out to develop a high-resolution gridded map of near surface temperature and humidity for Kathmandu valley and its immediate surrounding areas as a starting point to address the foreseen problem of climate change and adaptation. Grid based seasonal and annual distribution map of near surface temperature and humidity have been developed as predicted by numerical simulation at horizontal resolution of $1 \mathrm{~km}^{2}$ with the application of WRF Modeling System initializing with NCEP meteorological and USGS land use and terrain elevation data. Model predictions agree well with the available observation data.
\end{abstract}

Keywords: Atmospheric Modeling, microclimate, climate mapping, Kathmandu valley.

\section{INTRODUCTION}

Mountainous region encompassing valleys and basins create their own characteristic microclimates by containing and channeling meteorological fields within their boundaries and having different radiation budgets on their slopes. Consequently, there could be tremendous variation in microclimate within very short distances and hence appears dramatically favorable and unfavorable for human comfort and agricultural activities. Understanding the microclimate of an area of interest and its incorporation into urban/regional planning is very important to conserve prevailing natural climate and environment over the area.

The Kathmandu valley, the capital of Nepal, has seen visible changes in its weather and climatic patterns and hence in its prevailing microclimate in recent decades. Precipitation, fog, cloud, temperature and even wind patterns that used to prevail over the Kathmandu valley a couple of decades ago have largely became the things of the past. These transformations may be attributed for turning the agro-forest dominated valley floor into a concrete jungle and heavily deforesting the outskirts and surrounding mountain slopes. As a result, the environment of Kathmandu valley has become increasingly uncomfortable, unhealthy and more susceptible to, so far, unanticipated viral and other diseases.
The lack of spatial distribution and temporal variation of baseline data of potential microclimatic parameters as well as future scenarios have given rise to serious uncertainties with respect to microclimate change and development of adaptation strategies for sustainable microclimate of the Kathmandu valley and beyond. An accurate assessment and gridded documentation of prevailing microclimate at desired resolution is instrumental in this regard. Thus, to begin with, the present study has been carried out to develop a gridded map of current near surface temperature and humidity for Kathmandu valley and its immediate surrounding areas.

Developing an accurate temperature and humidity distribution map over Kathmandu's complex terrain is a challenging task as this is the region where the local circulations associated with a large number of small-scale subdivisions and sub-climates existing in the region interact in a complicated manner (Regmi et al. 2003). However, as techniques have improved greatly in recent years, it is possible to realize a realistic assessment of potential microclimatic parameters such as temperature and humidity taking advantage of regional scale meteorological models usefully complemented with field observations. Past studies and experiences on the prevailing meteorology (Regmi et al. 2003; Regmi \& Maharjan, 2013) over the valley have 
clearly demonstrated that characteristics distribution of temperature and humidity can be numerically simulated at desired resolution with the applications of mesoscale meteorological models.

\section{MATERIALS AND METHODS}

The third generation Weather Research and Forecasting WRF Modeling System (Skamarock et al. 2008) with core ARW has been applied to compute and to map the spatial distribution and seasonal variation of temperature and relative humidity both at 2 meters height above the ground level over an area of $51 \mathrm{~km} \times 51 \mathrm{~km}$ that covers the Kathmandu valley and its immediate surrounding areas. It is a fully compressible and non-hydrostatic model with a run-time hydrostatic option. The model utilizes a terrain-following hydrostatic pressure coordinate system, Arakawa C-grid staggering and Runge-Kutta $2^{\text {nd }}$ and $3^{\text {rd }}$ order time integration schemes, and 2 nd to 6 th order advection schemes in both the horizontal and vertical, thus, making highly suitable to perform simulation over a highly complex terrain.

The model was conFig.d based on test sensitivities that best suited for Kathmandu valley (Regmi \& Maharjan, 2013; Regmi, 2013). A triply-nested two-way interacting mesh of $51 \times 51 \times 34$ grid points with horizontal grid sizes 9, 3, $1 \mathrm{~km}$ for coarse, fine, and finest domains, respectively, was sued for this calculation (see Fig. 1 for domain configuration and area coverage). The physics options/schemes used in this calculation include WSM 3-class simple ice, Kain-Fritsch (for coarse domain only), Unified NOAH land-surface, YSU Planetary Boundary Layer, RRTM long wave, and Dhudhia short wave etc. The model was initialized with $1^{\circ} \times 1^{\circ} 1^{\circ} \times 1^{\circ}$ horizontal resolution 6 hourly operational meteorological data from National Centers for Environmental Prediction (NCEP) and the 24 categories land use and 30 second terrain elevation data by United States Geological Survey (USGS). The WRF model is initialized at 0000 UTC of a given day and is run for 48 simulated hours, storing the output every hour. The first day of the simulation is discarded as a spin up of the model, and the values for the following 24 hours are retained as the simulation for that day. The process is repeated until a simulation for all days of the year 2012 .

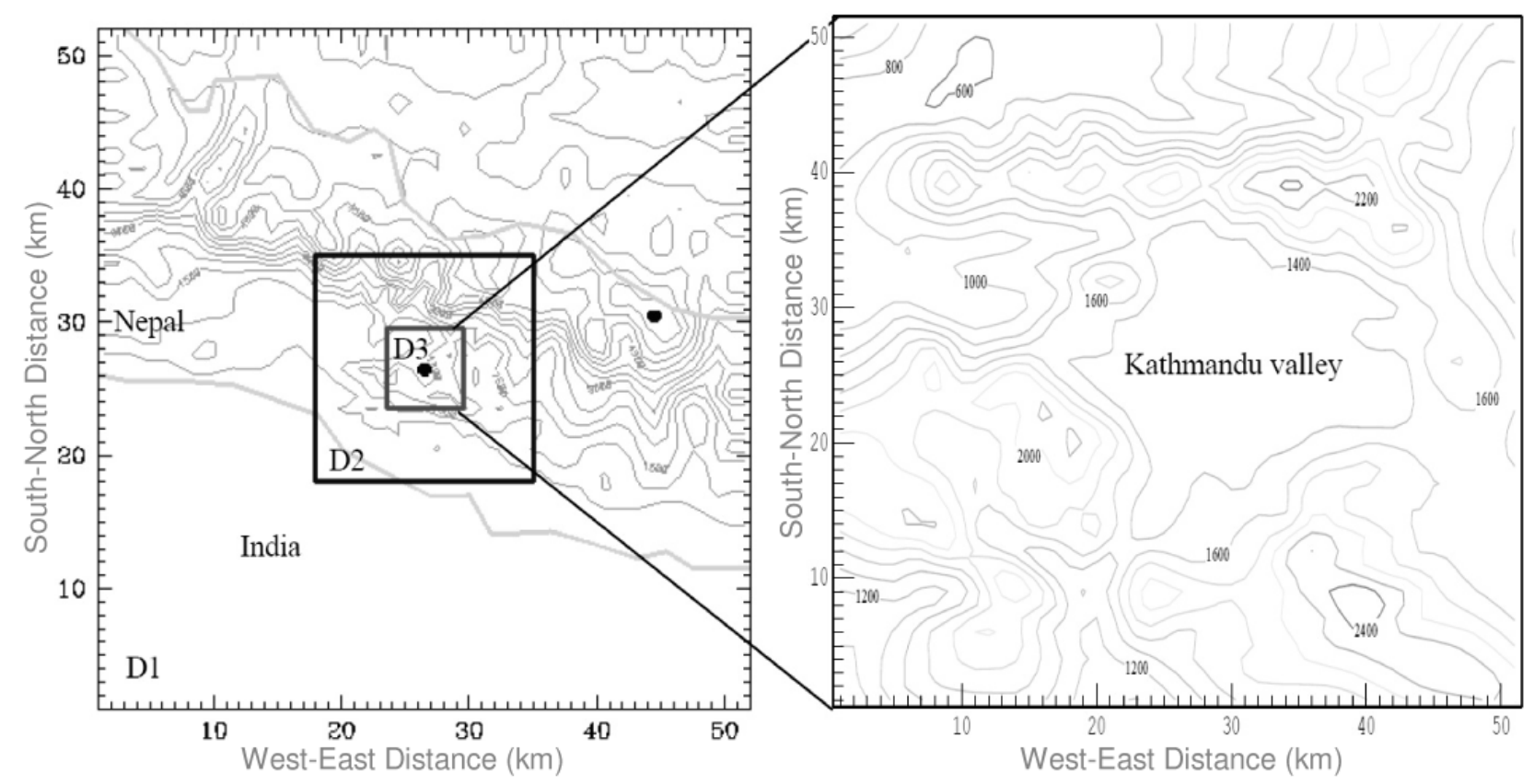

Fig. 1. Calculation domain configuration: D1, D2, and D3 represent the coarse, fine and the finest domains of horizontal grid resolution of $9 \mathrm{~km}, 3 \mathrm{~km}$, and $1 \mathrm{~km}$, respectively. All the domains are centered at the center of the Kathmandu valley $\left(27.7^{\circ} \mathrm{N}, 85.3^{\circ} \mathrm{E}\right)$. Inset shows the detail terrain structure of the Kathmandu valley and its immediate surroundings. 


\section{RESULTS}

\section{Rationale of numerical prediction}

The near surface temperature and humidity climatology of Kathmandu valley has been prepared as predicted for the year 2012. As the weather station of CDP came into operation since August 2012, we could only make comparison of model calculation with observation only for the months of September to December 2012.
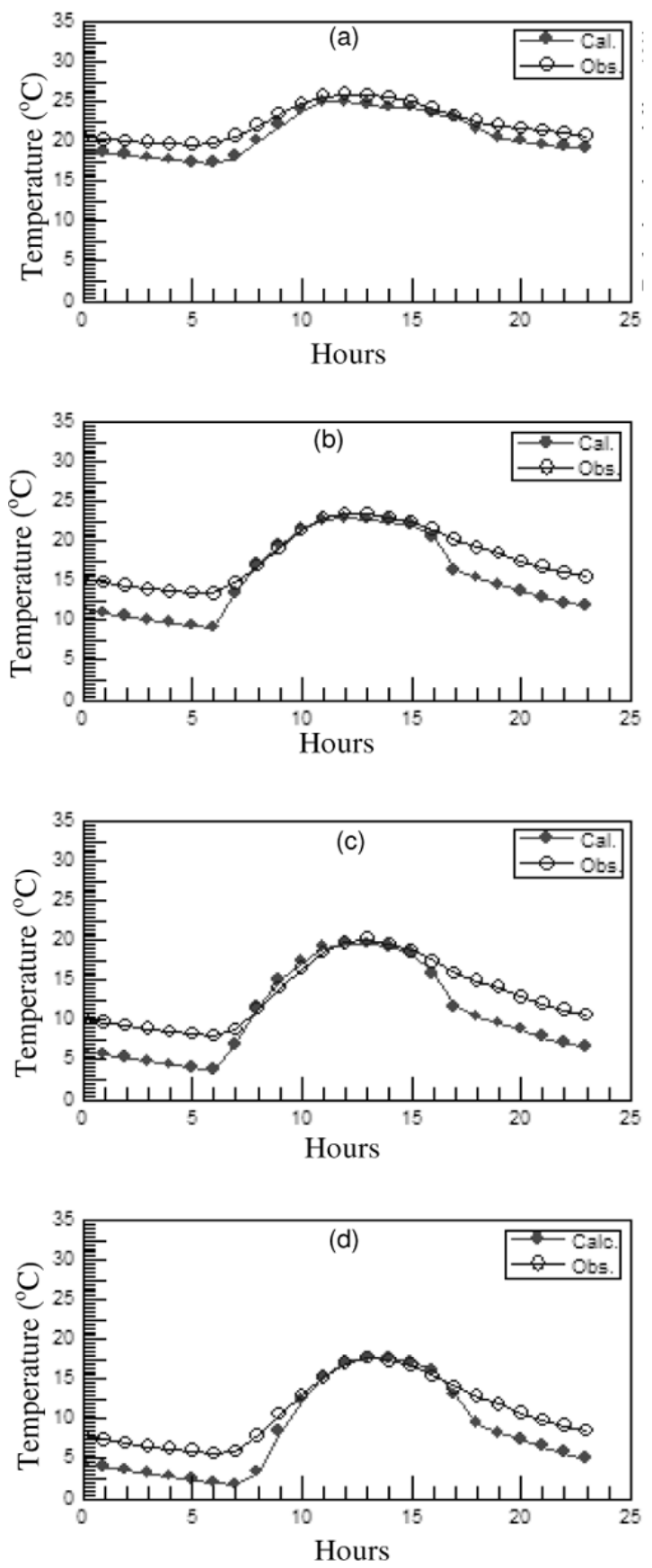

Fig. 2. Graphical comparison of model predictions at $2 \mathrm{~m}$ and observation at $5 \mathrm{~m}$ AGL of relative humidity (a-d) and temperature (e-h). 
The model predicts temperature and humidity at 2 meters height above the ground whereas the measurements have been made at 5 meters above the surface. Moreover, the temperature and humidity sensors have been setup at the top of one story concrete building rather than in the standard open grassland. These factors should have leaded to the differences in the calculation and observations values, particularly, during the night and morning times in the case of temperature.

\section{Seasonal distribution of temperature}

Figs. 3a-d show the mean surface temperature distribution over the Kathmandu valley and its surrounding areas in four different seasons as revealed by numerical simulations. Comparing the surface temperature distribution map, it can be said that the surrounding
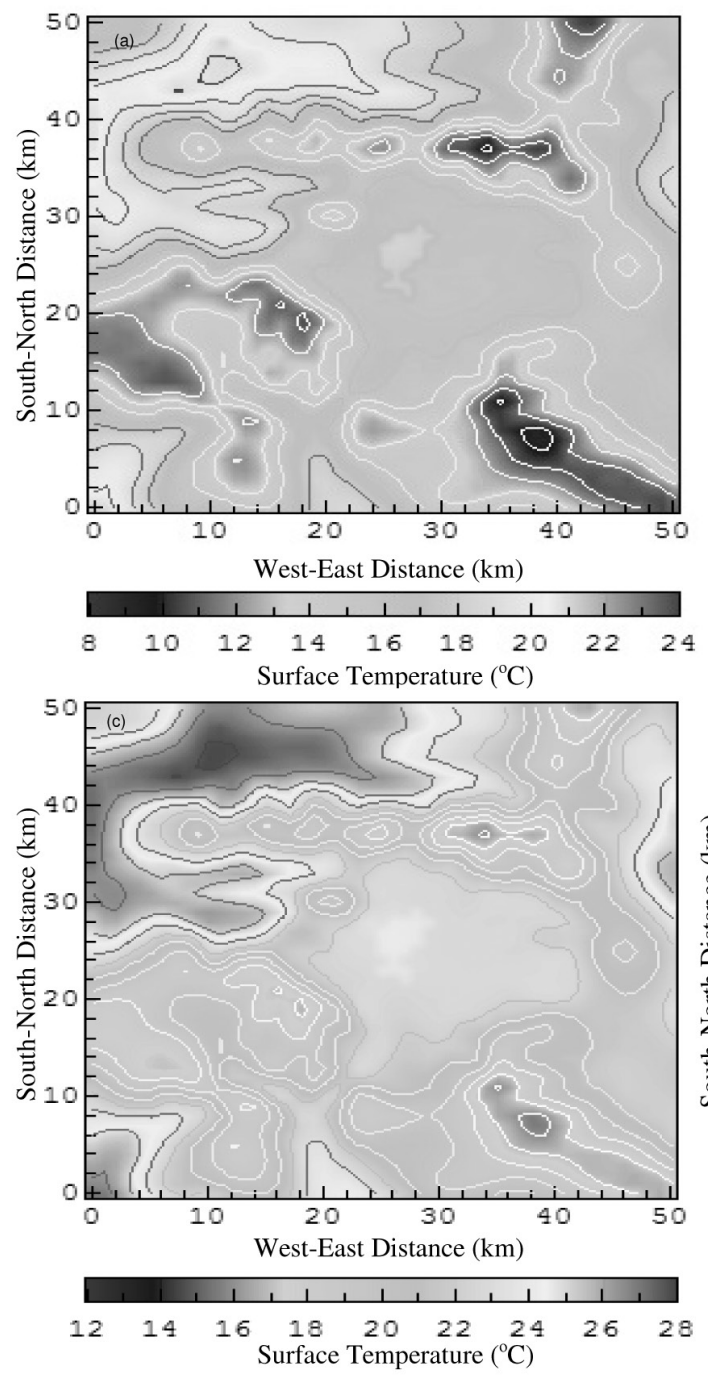

mountain ridges are comparatively cooler than the valley floor in all seasons. The mean surface temperature over Fulchoki Mountain appears to 2 degree Celsius in winter season, coldest region near the valley. Like Fulchoki, other surrounding mountain ridges such as Shivapuri and Champadevi also appear to posses very low temperature close to Fulchoki but rather warmer compared to it. Nagarkot and Nagarjung Mountain ridges appear to posses mean temperature of about 19 degrees Celsius in summer and about 7 degrees Celsius in winter.

The valley floor remains always remains comparatively very warmer in all the seasons although Kathmandu valley accumulates cold air during the night time whose depth may reach up to 400 meters in the early morning during the winter time (Regmi et al. 2003).
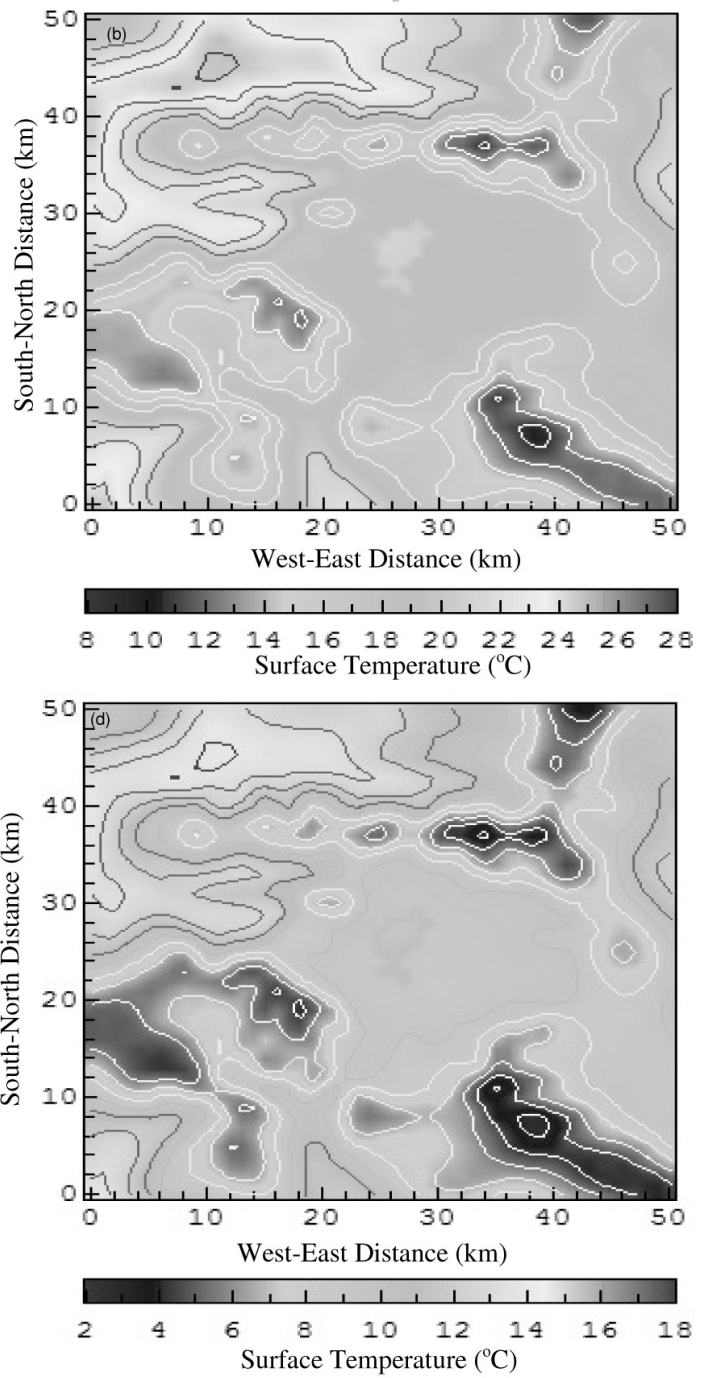

Fig. 3. Spatial distributions of mean temperature at 2 m AGL over the Kathmandu valley and its surrounding areas in autumn (a), spring (b), summer (c), and winter (d). 
It is interesting to note that within the valley floor area enclosed by terrain contour of 1400 meters a chunk of north-western central area (possibly over the Kathmandu City Area) appears to possess rather warm climate compared other parts of the valley floor in all the four seasons. The average temperature of this particular area tends to be around 19, 22, 24, and 10 degree Celsius during autumn, spring, summer and winter season respectively, which area about 2 degree higher compared to the temperature prevailing over the remaining area of the valley floor. The western and northwestern neighboring (Dhadhing \& Trishuli) valleys as well as the southwestern area appear be warmest in all the seasons. During summer, their mean temperature is close to 28 degree Celsius and in winter it decreases to 15 degree Celsius.
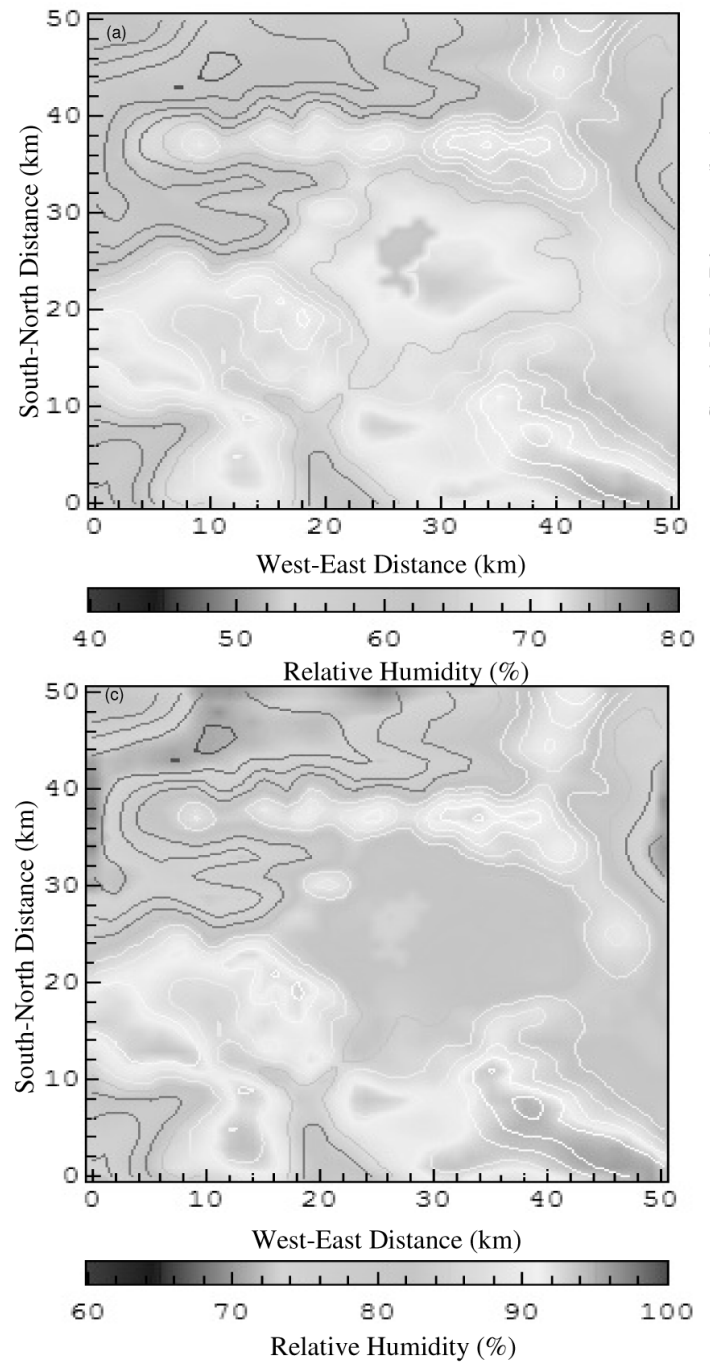

\section{Seasonal distribution of humidity}

Figs. 4a-d show the seasonal average relative humidity at 2 meters AGL over the Kathmandu valley and its surrounding areas as revealed by numerical simulations. Comparing with the distribution of temperature (Fig. 3a-d) and humidity (Figs. 4a-d), it can be clearly seen that humidity and temperature distribution are inverse distribution pattern, i.e., the areas with higher temperature possess lower humidity. The relative humidity over the surrounding mountain ridges of the valley in general and, particularly, the Fulchoki Mountainous area appear to posses maximum relative humidity whereas the western and northwestern low-and valleys, namely, Dhading and Trishuli valleys posses lowest level of humidity in all the seasons.
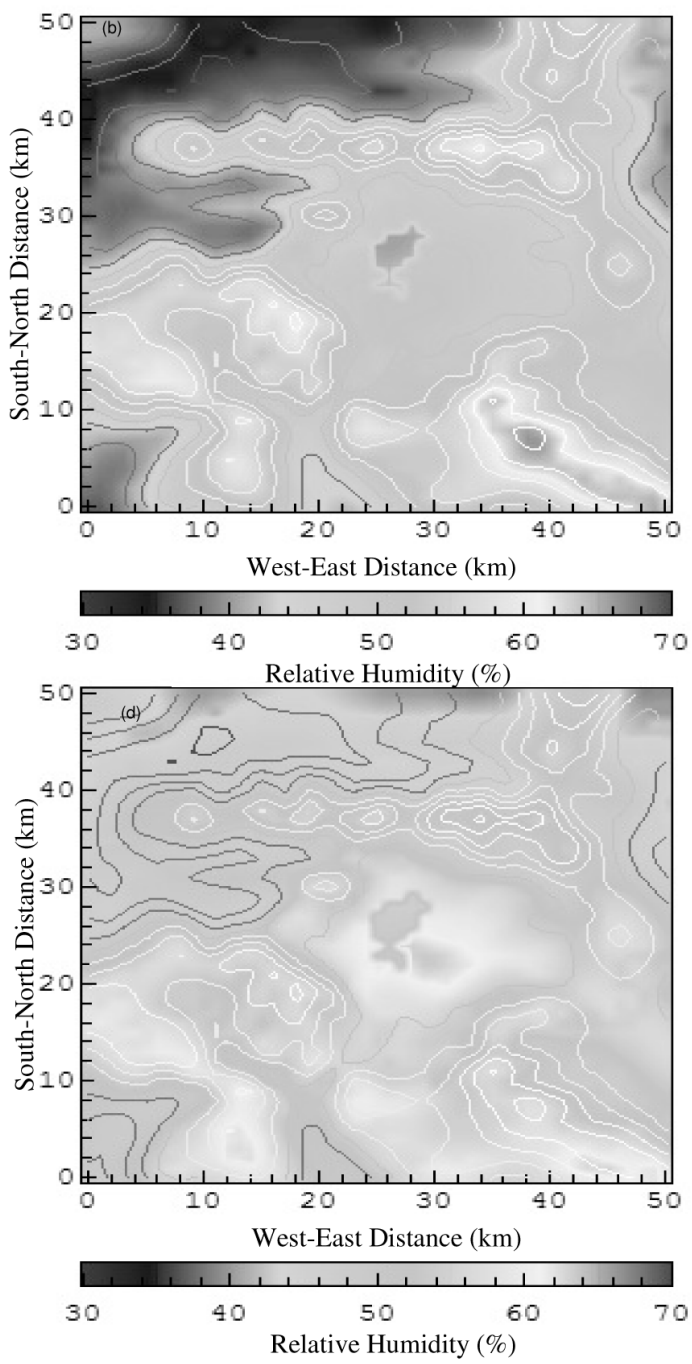

Fig. 4. Spatial distribution of relative humidity at 2 meters AGL over the Kathmandu valley and its immediate surroundings in autumn (a), spring (b), summer (c) and winter (d). 
The relative humidity over Fulchoki Mountain ridge appears more than 70 percent in autumn, spring and winter where as it reaches to about 100 percent during summer. Shivapuri Mountain ridge in North and Champadevi Mountain ridge located in the southwest also show similar characteristics as Fulchoki Mountain ridges. During autumn, large landmasses covering valley floor and surrounding mountain ridge possesses relative humidity between $60-75$ percent whereas it tend to be around 50-65 percent during spring and winter. However, there appears a sudden rise in humidity. As relative humidity usually decrease with increase in temperature so Nagarkot Mountain ridge has greater relative humidity than valley floor and lesser than Fulchoki Mountain ridge. Its value tends close to about 40 percent during spring. Like in the case of temperature distribution, a chunk of area in northwestern central area of the valley floor possesses rather less level humidity compared to other parts of the valley floor. It is interesting to note that the core central area of the valley floor appears to be very humid and is comparable to the level of humidity over

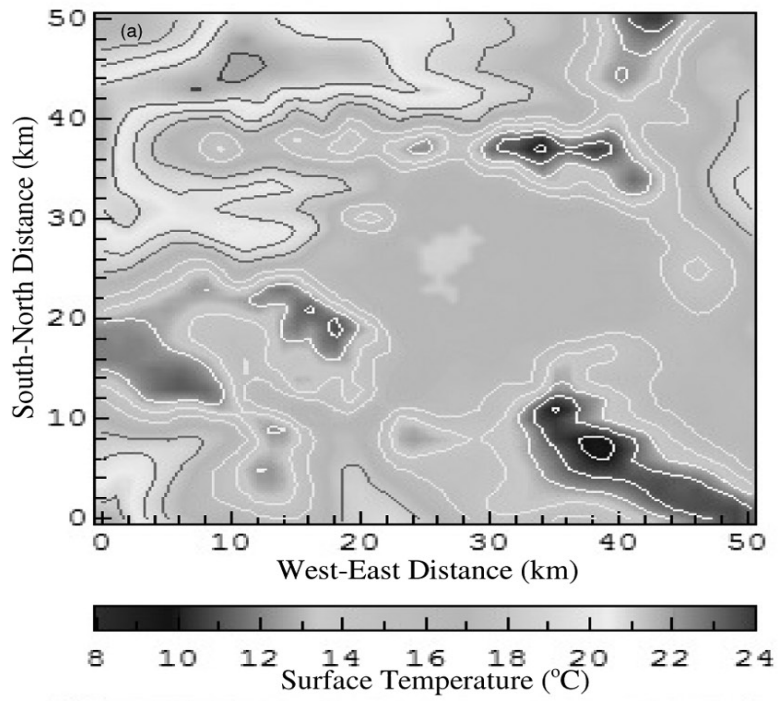

the Fulchoki Mountain ridges during the autumn and winter seasons.

\section{Annual distribution of temperature and relative humidity}

Figs. 5a-b show the annual spatial distribution of temperature and relative humidity at 2 meters AGL. The annual average maximum and minimum temperature over the whole study area are about 23 and 10 degree Celsius, respectively. Similarly, the annual average maximum and minimum relative humidity over the study area is about 52 and 74 percent, respectively. The annual mean temperature of the Kathmandu valley floor is about 18 degree Celsius and 68 percent relative humidity. In annual distribution also shows that small chunk of area in northwestern central area (possibly the city area of Kathmandu) of the valley floor possess relatively higher values of both the temperature and relative humidity. Fulchoki, Shivapuri, and Champadevi Mountain ridges possess lower temperature and higher relative humidity than valley floor throughout the year.

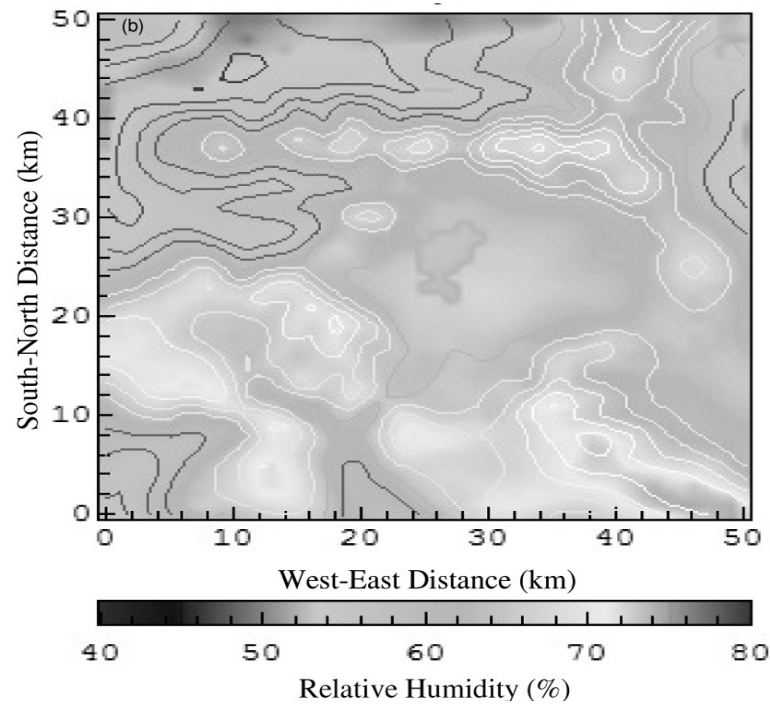

Fig. 5. Annual average spatial distributions of temperature (a) and relative humidity (b) over the Kathmandu valley and its immediate surrounding area.

This shows that the climate of Kathmandu valley as revealed by present study is still pleasant and comfortable.

\section{CONCLUSIONS}

Seasonal distribution of mean surface temperature and relative humidity both at $2 \mathrm{~m}$ AGL over the Kathmandu valley and its immediate surrounding areas have been numerically simulated with the application of the state-ofthe-art-of-the Weather Research and Forecasting (WRF) model. The numerical simulation reproduced a realistic distribution of temperature and humidity as expected from general perception and understanding. The good agreement between the observed values of temperature and relative humidity, though only limited observed data were available to compare, strongly support the above assertion.

The study revealed that the Fulchoki, Shivapuri and Champadevi Mountain ridges are cooler throughout the year. In the winter season, the average temperature 
reduces to 2 degree Celsius over Fulchoki Mountain ridge. The western and northwestern neighboring valleys, namely, Dhading and Trishuli valleys, respectively, appear warmest and less humid within the area calculation domain. Over the Trishuli valley, the summer and winter season mean temperature may reach around 28 and 15 degree Celsius respectively. The mean temperature over the Kathmandu valley floor ranges in between 7 and 22 degree Celsius during the winter and summer season respectively. However, a chunk of area in the northwestern central area where the core city of Kathmandu is located shows the nature of heat island as temperature of this area appears significantly higher (about 2 degree Celsius) compared to other parts of the valley floor. Unlike the city area of Kathmandu, the city areas of Lalitpur and Bhaktapur do not so such nature. Relatively higher temperature in this area compared to other parts of valley floor was also predicted in a weak long study of meteorological flows and air pollution transport over the valley during the late wintertime (Regmi et al. 2003; Kitata \& Regmi, 2003) which was attributed for the intrusion of relatively warm air from western low mountain passes that makes hydraulic jump like flow over the area. Many years of temperature records at Lainchaur (DHM, 2000) as well show significantly higher mean temperature compared to the temperature in other parts of the valley floor.

The relative humidity distribution over the valley floor shows that the southern central area of the valley is most humid and northwestern central area of the valley is least humid. The southern and southwestern mountain ridges are relatively more humid compared to other surrounding ridges. The most humid area over the calculation domain appears to be the Fulchoki Mountain ridges. The Trishuli and Dhading valleys and particularly the Trishuli valley appear to possess the least humidity within the study area.

However, it should be noted that present findings are based only on a yearlong simulation and numerical predictions could be validated with the limited data observed at a single surface observatory in Kirtipur. Thus, further in-depth numerical simulation studies for the period of at least 5-10 years and its rigorous validation with observations from meteorological observatories scattered over the Kathmandu valley would be necessary to derive definite conclusions and to assess the change in typical microclimate of the valley as well as to develop heat index charts which can give new dimension in the study of thermal comfort, agricultural production, health etc. over the Kathmandu valley and beyond.

\section{ACKNOWLEDGEMENTS}

This research was partially supported by the University Grant Commission, Nepal under its Institutional Grant Research Project.

\section{REFERANCES}

DHM, 1995. Department of Hydrology and Meteorology, Babar Mahal, Kathmandu, Nepal.

Kitada, T. and Regmi, R.P. 2003. Air pollutants distribution and their dynamics over the Kathmandu valley, Nepal: As revealed with numerical simulation. J. Appl. Meteo. 42:1770-1789.

Regmi, R.P. 2013. Springtime Windstorm in the Kathmandu Valley and its Predictability. Journal of Institute of Science and Technology 18(2):28-36.

Regmi, R.P. and Maharjan, S. 2013. Wind Power Density over the Kathmandu Valley and its Surrounding Areas. Journal of Institute of Science and Technology 18(1): 4349.

Regmi, R.P., Kitada, T. and Kurata, G. 2003. Numerical simulation of late wintertime local flows in the Kathmandu valley, Nepal: Implication for air pollution transport. J. Appl. Meteo. 42: 389-403.

Skamarock, W. C. et al. 2008. A description of the advanced research wrf version 3 . Tech. Rep. NCAR/TN-475+STR, Mesoscale and Microscale Meteorology Division, National Center for Atmospheric Research, Boulder, Colorado, USA, 113 pp. 